\title{
Dança do chorado: reescriturações de sentidos para a dançarina
}

\author{
Dance of the Chorado: Rewriting of senses to the dance
}

\author{
Weverton Ortiz Fernandes ${ }^{1}$ \\ Universidade do Estado de Mato Grosso
}

Fátima Graziele de Souza ${ }^{2}$

Universidade do Estado de Mato Grosso

Albano Dalla Pria ${ }^{3}$

Universidade do Estado de Mato Grosso

\begin{abstract}
- RESUMO: Nesta pesquisa tomamos como objeto de estudo uma narrativa sobre a Dança do Chorado, referente ao período colonial e imperial, enunciada no ano de 2008 em Vila Bela - MT. Temos como objetivo compreender a significação dos nomes para as figuras femininas, nomeadas de senhoras escravas, senhoras e conselheiras da festança. Por buscarmos compreender o modo como os nomes significam, filiamos o presente estudo nos pressupostos teóricos da Semântica do Acontecimento (Guimarães, 2002, 2005). Na pesquisa, compreendemos que as designações atestam o lugar social das dançarinas da Dança do Chorado. Na narrativa, senhoras escravas e senhoras predicam sentidos de estrategistas, mulheres diferenciadas e bem melhor tratadas. Já conselheiras da festança predica sentidos de liberdade das dançarinas, opondo-se aos sentidos de senhoras escravas. Pelas reescriturações compreendemos que senhoras escravas / senhoras / conselheiras da festança reatualizam sentidos, em que as designações significam a mulher pelos sentidos de cortesia, distante dos sentidos de desprestígios que eram significadas no contexto social do período da escravidão. Assim, compreendemos que a nomeação senhoras escravas / senhoras / conselheiras da festança, nas condições atuais em que foi enunciada, rompe com a história de significação dos negros do período colonial.
\end{abstract}

- PALAVRAS-CHAVE: Dança do Chorado. Senhoras Escravas. Designação. Reescrituração.

- ABSTRACT: In this research we take as object of study a narrative about the Chorado Dance, referring to the colonial and imperial period, enunciated in the year of 2008 in Vila Bela City - Mato Grosso State. We aim to understand the meaning of the names for the female figures, named slaves ladies, ladies and counselors of the feast. Because we try to understand how names mean, we have affiliated the present study with the theoretical assumptions of Semantics of the Event (Guimarães, 2002, 2005). In the research, we understand that the designations attest to the social place of the Dancers of Chorado Dance. In the narrative, slaves ladies and ladies preach senses of strategists, different women and better treated. While the counselors of the feast preach senses of freedom of the dancers, opposing to the senses of slave ladies. By the rewrites we understand that slave ladies / ladies / counselors of the feast reactualized senses, in that designations mean the woman by the courtesy senses, far from the senses of deprivations that were meant in the social context of the period of slavery. Thus, we understand that the nomination of slaves ladies/ ladies / counselors of the feast, under the present conditions in which it was enunciated, breaks with the history of signification of the blacks of the colonial period.

- KEYWORDS: Dance of the Chorado. Ladies Slaves. Designation. Rewriting.

\footnotetext{
1 Mestre em Linguística pela UNEMAT. Doutorando do Programa de Pós-Graduação em Linguística da UNEMAT/Cáceres.

2 Graduada em Letras pela UNEMAT/Cáceres. Mestranda do Programa de Pós-Graduação em Linguística da UNEMAT/Cáceres.

${ }^{3}$ Pós-Doutor pela Universidade Nova de Lisboa (Bolsista CAPES - Proc. no 99999.006159/2014-01). Doutor em Linguística e Língua Portuguesa pela UNESP/Araraquara. Docente do Curso de Letras da UNEMAT/Alto Araguaia e do Programa de Pós-graduação em Linguística da UNEMAT/Cáceres. Coordenador do Grupo de Pesquisa Variação e invariantes na linguagem. adallapria@gmail.com
} 


\section{Apresentação}

Tomamos como objeto de estudo uma narrativa sobre a Dança do Chorado, narrada no ano de 2008, na cidade de Vila Bela da Santíssima Trindade - MT. A Dança do Chorado é originária desta cidade, fundada em 1752 para ser a primeira capital de Mato Grosso. Vila Bela funcionou como um ponto estratégico da Coroa Portuguesa, que visava ampliar as fronteiras do Brasil e extrair as principais riquezas minerais dessa região, tendo o trabalho escravo como a principal mão de obra.

Como forma de resistência dos negros à submissão de não poder dizer, surgiu a Dança do Chorado: uma dança sedutora encenada apenas por mulheres escravas, e que funcionava como uma forma de fazer pedidos aos coronéis. O período em que a Dança surgiu coincide com a condição dos escravos na sociedade, conforme considera Zattar (2000):

[...] não era possível ao escravo assumir uma posição-sujeito que não fosse a determinada pelas instituições que o regiam. Como consequência dessas relações, verifica-se que uma parte significativa da sociedade brasileira colonial e imperial não enunciava, não tinha o direito à voz, sendo o seu lugar na enunciação representado/ocupado pela classe que a dominava. Nessa perspectiva, não-ser-livre é não enunciar, não-ser-livre é não dizer, não-serlivre é estar excluído do ato de dizer (ZATTAR, 2000, p. 12).

Os primórdios da Dança do Chorado remetem ao período em que o escravo era tido como objeto de direito. Um pouco distante do que considera Zattar (2000), a narrativa sobre o Chorado aponta para um ritual ${ }^{4}$ que reencena o pedido dos negros aos coronéis, especificamente das mulheres aos seus superiores. Ou seja, a Dança funcionava como uma forma das mulheres escravas poderem dizer em um momento que não podiam dizer. Por ser uma dança de estilo sedutor, as mulheres se caracterizavam com vestidos longos e equilibravam uma garrafa de aguardente na cabeça, com o objetivo de atrair as atenções dos senhores proprietários de terra. Quando os coronéis eram seduzidos pela Dança, em troca de favores sexuais, as mulheres pediam a libertação dos escravos, entes queridos, que estavam condenados à tortura e à morte.

Nesse sentido que se compreende o primeiro período da Dança do Chorado, dado que as diversas versões da Dança a constituem em três períodos. Se, no primeiro período, a Dança do Chorado ${ }^{5}$ funcionou como uma linguagem de sedução, no segundo período, que remete à transferência da capital para Cuiabá, o Chorado passou a ser praticado em recinto fechado e organizado apenas pelas mulheres chamadas de conselheiras da festança, já que esse período coincide com o momento de ruptura do trabalho escravo na região de Vila Bela.

No último período, a partir do final da década de 80 (oitenta), a Dança do Chorado passou a ser organizada pelas mulheres descendentes de escravas, contando com o apoio da comunidade local. Nesse terceiro momento, a Dança do Chorado funciona como reatualização dos sentidos de sua cena primeira, em que os sentidos de tradição ensejam os seus festejos na atualidade.

Referentes ao primeiro e segundo períodos, propomos compreender o modo como a escrava aparece designada nesse acontecimento de linguagem. Para isso,

\footnotetext{
${ }^{4}$ Consulte-se Fernandes (2014) sobre a descrição do ritual.

${ }^{5}$ Compreenderemos a Dança do Chorado e a narrativa sobre o Chorado como um acontecimento de linguagem, no sentido tratado por Guimarães (2002).
} 
faremos um contraponto entre a condição jurídica das escravas à época e os sentidos que a significam no acontecimento da Dança do Chorado na atualidade.

Fundadas nessas considerações, formulamos a seguinte problematização: no interior da narrativa, que sentidos são produzidos na designação senhoras escravas, senhoras e conselheiras da festança?

\section{Considerações teóricas}

Fundamentamos as análises, acerca da narrativa do Chorado, na perspectiva da Semântica do Acontecimento (GUIMARÃES, 2002, 2005). Propomos refletir sobre as reescriturações dos sentidos dados às dançarinas. Partindo do princípio de que as reescriturações das dançarinas estão numa relação com os sentidos postos pela enunciação, Guimarães (2002), considera a enunciação "enquanto acontecimento de linguagem, [que] se faz pelo funcionamento da língua" (p. 11). Parafraseando o autor, supomos o funcionamento linguístico da narrativa como acontecimento de linguagem.

No acontecimento de linguagem, inclui-se a história e o sujeito (Guimarães, 2002). O sujeito é descentralizado pelo acontecimento, tomado pela temporalidade. Assim se pronuncia Guimarães (2002): "O que quero dizer que não é o sujeito que temporaliza, é o acontecimento. O sujeito não é assim a origem do tempo da linguagem. O sujeito é tomado na temporalidade do acontecimento" (GUIMARÃES, 2002, p. 12). Desse ponto de vista, pela Semântica do Acontecimento, o sujeito descentrado é aquele inscrito no acontecimento da linguagem.

Do aparato teórico-metodológico da Semântica do Acontecimento, mobilizamos o conceito de designação, que será compreendido numa relação com as nomeações das dançarinas da Dança do Chorado. O conceito de designação define-se como:

[...] o que se poderia chamar de significação de um nome, mas não enquanto algo abstrato. Seria a significação enquanto algo próprio das relações de linguagem, mas enquanto uma relação linguística (simbólica) remetida ao real, exposta ao real, ou seja, enquanto uma relação tomada na história. É neste sentido que não vou tomar o nome como uma palavra que classifica objetos, incluindo-os em certos conjuntos (GUIMARÃES, 2002, p. 9).

Com efeito, a designação do nome não se confunde com a classificação de um objeto, e muito menos com a intencionalidade do sujeito. A significação dos nomes é constitutiva do real e nela. Está nele imbricados a história e o político próprios do funcionamento linguístico.

Além disso, analisamos os pronomes e as reescriturações (GUIMARÃES, 2011, p. 210 como elementos integrados ao texto, ou seja, ao estudarmos as reescriturações, visando compreendê-las como integradas à narrativa.

\section{As designações e as reescriturações na narrativa do Chorado}

Recortamos, para o estudo, quatro enunciados da narrativa que reescritura os sentidos de senhoras escravas. Seguem adiante os recortes.

a) A Dança do Chorado foi uma estratégica usado pelas senhoras escravas no momento correto...

b) Seus esposos e seus filhos presos, além de tudo isso e conhecimento da população, os sacrifícios são dados até as solturas que eram feito diante da presença dessas senhoras. 
c) As senhoras tinham uma certa diferenciação: era bem melhor tratadas.

d) E os tempos se passaram. Após a transferência da capital de Vila Bela pra Cuiabá, a festa do Chorado, a dança do Chorado, perderam seu sentido. Mas no entanto, as conselheiras da festança assumiram essa responsabilidade[...]

Nos três primeiros recortes, o pronome senhoras $^{6}$ historiciza sentidos de cortesia, prestígio, cerimônia e, nesses enunciados, o pronome funciona como uma forma de prestígio às escravas. Esse modo de dizer não coincide com o tratamento dado aos negros nos períodos colonial e imperial: "São tratados com respeito e cerimônia os que são livres e, portanto, enunciam" (ZATTAR, Idem). Ou seja, a narrativa se constitui por sentidos de cortesia, agenciados no acontecimento enunciativo da atualidade, e não mais pelos sentidos de posse, de objeto, como eram nos primórdios da Dança. No período colonial, a nomeação do escravo, conforme Zattar (2000), ocorria do seguinte modo:

Como efeito de evidência, o escravo, seja de origem africana ou brasileira, significava pelas características que aparentemente os futuros proprietários viam nele. Eram, portanto, os traços perceptíveis no escravo que identificavam nos espaços urbanos e rurais (ZATTAR, 2000, p. 48).

Como não se dava o tratamento cerimonioso ao escravo, constrói-se na narrativa sobre a Dança do Chorado a tensão: por um lado, a narrativa refere as dançarinas, negras, escravas, da cena primeira, através do tratamento de cortesia, por outro lado sentidos esses socialmente interditados ao escravo, nessa época. Essas designações são consequentes para as reescriturações, compreendidas, em b) e c), pelo pronome senhoras, que substitui o nome escravas.

A dança do Chorado foi uma estratégica usado pelas senhoras escravas no momento correto com a dancinha. Seus esposos e seus filhos presos, além de tudo isso e conhecimento da população, os sacrifícios são dados até as solturas que eram feitas na presença dessas senhoras. As senhoras tinham uma certa diferenciação: eram bem melhor tratadas. (ANEXO)

Através da reescrituração, senhoras substitui senhoras escravas. Um DSD (Domínio Semântico de Determinação) pode exemplificar os sentidos das designações:

\begin{tabular}{|c|}
\hline DSD 1 \\
Dançarinas \\
$\perp$ \\
senhoras escravas - senhoras + bem melhor tratadas \\
\hline
\end{tabular}

Leia-se: Dançarinas determina senhoras escravas que está em processo de sinonímia com senhoras. Nesse sentido, senhoras é determinada por bem melhor tratadas

Observe-se que temos um processo de reescrituração por condensação. Nesse sentido, o recorte apresentado possibilita-nos compreender que a designação dada às dançarinas significa senhoras escravas numa relação de sinonímia com senhoras. Isso só é possível porque temos a reescrituração por condensação, pois, senhoras, nesse recorte, é determinada por "bem melhor tratadas". Parafraseamos da seguinte maneira:

\footnotetext{
${ }^{6}$ Consulte-se Cunha e Cintra (1985) sobre a definição dos pronomes.
} 
Paráfrase 1. "As senhoras tinham uma certa diferenciação: era bem melhor tratadas" por "As senhoras escravas dançarinas tinham um tratamento melhor do que as outras escravas".

Desse modo, compreendemos que os recortes b) e c) reescrituram os sentidos de prestígio e de desprestígio: o pronome de tratamento de prestígio senhoras, ao substituir escravas, nome que remete à condição da mulher que vivia sob o poder de seu proprietário, também significa sentidos de escrava - desprestígio - submissão, são sentidos estes que vazam pela história e imbricam na reescrituração do pronome senhoras. Quer dizer, a reescrituração do pronome senhoras significa prestígio e desprestígio para as dançarinas de sua cena primeira. Isso rompe com a gramática tradicional, no sentido de que senhoras é apenas um tratamento pessoal de prestígio.

No processo de reescrituração, compreende-se que os pronomes produzem sentidos distintos. No primeiro recorte, a relação senhoras com escravas é linear. No segundo recorte, a relação de senhoras reescritura senhoras escravas e refere os sacrifícios, a luta das escravas, que buscavam a libertação de seus entes condenados. Já no terceiro recorte, o pronome senhoras reescritura sentidos de mulher, negra, dançarina e diferencia em relação aos demais escravos.

$\mathrm{Na}$ sequência da narrativa, aparece a terceira reescrituração: as conselheiras da festança, que tem como referência o segundo período da Dança do Chorado, quando as conselheiras da festança procuraram ressignificar os sentidos da origem da Dança. Veja-se:

E os tempos se passaram. Após a transferência da capital de Vila Bela pra Cuiabá, a festa do Chorado, a dança do Chorado, perderam seu sentido ${ }^{7}$. Mas no entanto, as conselheiras da festança assumiram essa responsabilidade, que ao final da festa, por elas não terem participado duma festança igual semelhante a essa, elas se reuniam em um determinado local, um pouco secreto, e "borrunfaram" os tambores. (ANEXO)

As conselheiras da festança eram as mulheres descendentes de escravos. Buscavam ressignificar os sentidos do Chorado em recintos fechados na forma de festas que não só não deixaram apagar a memória das conquistas das escravas, mas também perpetuaram a Dança.

As nomeações de senhoras escravas para conselheiras da festança indicam a mudança político e social no curso da Dança: enquanto senhoras escravas têm como referência o período em que as praticantes eram escravas, conselheiras da festança têm como referência o período em que as dançarinas eram livres, juridicamente. Nesse acontecimento, conselheiras da festança significa "mulher livre" pela responsabilidade assumida por elas na prática da Dança. Exemplificamos na forma de paráfrase:

Paráfrase 2. As mulheres da festança assumiram a responsabilidade em organizar a Dança do Chorado.

Assumir a responsabilidade significa ser livre. Os sentidos sobre as mudanças vivenciadas pela comunidade vilabelense se instituem na designação dos nomes das dançarinas do Chorado. Com o DSD 2 podemos compreender melhor não a mudança do

\footnotetext{
${ }^{7}$ Ressaltamos que a transferência da capital para Cuiabá (1835) coincide com o decreto regional em Vila Bela que libertava os escravos do regime da escravidão.
} 
cenário social em Vila Bela, mas o político instalado na língua ao designar a mulher da Dança.

\begin{tabular}{|c|}
\hline DSD 2 \\
Dançarinas $\dashv$ senhoras escravas - senhoras \\
$\frac{\text { conselheiras da festança }}{}$
\end{tabular}

Leia-se: Senhoras escravas é determinada por dançarinas. Por sua vez, senhoras escravas está numa relação do processo de sinonímia com senhoras, que obtém uma relação de antonímia com conselheiras da festança.

Conselheiras da festança opõe-se aos sentidos de senhoras escravas. O DSD acima contrasta o primeiro com o segundo momento da Dança do Chorado: mulher escrava / conselheiras da festança. Contrasta, ainda, o momento da Dança com o locutor. O locutor-narrador está tomado pelo acontecimento da linguagem, lugar social de dizer do sujeito. No acontecimento de linguagem, o locutor-narrador ao dizer senhoras escravas / senhoras / conselheiras da festança, também se diz tomado por um enunciador-coletivo da Dança do Chorado: a história, os sentidos sobre/para a festa, o prestígio da dança e das praticantes sustentam a narrativa.

O político se institui na língua pelo dizer, conforme ressalta Guimarães (2002). A enunciação é marcada pelo confronto dos sentidos, pela divisão: o dizer de senhoras escravas opõe-se ao dizer de escravas. O agenciamento de sentidos bloqueia o locutornarrador na escolha de enunciar do lugar que the melhor convém. A enunciação senhoras escravas agencia o lugar de cortesia do locutor-narrador ao dizer sobre a Dança do Chorado.

\footnotetext{
Deste modo considero que o falante, tal como o conceituo, é uma categoria linguística e enunciativa. Minha diferença está em que considero que o falante não é esta figura empírica, mas uma figura política constituída pelos espaços de enunciação. E nesta medida ela deve ser incluída entre as figuras da enunciação. Os espaços de enunciação são espaços habitados por falantes, ou seja, por sujeitos divididos por seus direitos ao dizer e aos modos de dizer (GUIMARÃES, 2002, p. 55 - grifo do autor).
}

As designações senhoras escravas e senhoras predicam sentidos referentes ao período da escravidão. Por certo, se a Dança do Chorado marca-se como uma dança surgida no período colonial, então a designação de praticantes da Dança marca esse período pela enunciação, assim como conselheiras da festança também reatualiza os sentidos de liberdade das negras de praticar o Chorado. A nomeação e o contexto social se traduzem nos modos de designação das praticantes.

As designações e as reescriturações de senhoras escravas, senhoras e conselheiras da festança institui, no interior dos enunciados, o embate dos sentidos (ou os sentidos em embate) sobre a Dança do Chorado, na atualidade.

\section{Considerações finais}

Concluímos que a designação das dançarinas resulta da construção de relações enunciativas próprias da linguagem. Observamos nas reescriturações modos distintos de nomear as escravas na Dança do Chorado. Inicialmente, pelo pronome-nome senhoras escravas, depois, pelo pronome senhoras e, por último, pelo nome as conselheiras da 
festança. Ao tomarmos esses nomes como designações, dentro do acontecimento de linguagem, pudemos apreender diferentes referentes para a mesma praticante.

Desse modo, as reescriturações atestam o lugar social do locutor-narrador da Dança do Chorado em Vila Bela da Santíssima Trindade - MT, que ao dizer de senhoras e conselheiras da festança reescritura sentidos outros de senhoras escravas. A reescrituração dos enunciados institui o funcionamento do político na língua.

\section{REFERÊNCIAS}

CUNHA, C.; CINTRA, L. F. L. Nova Gramática do Português Contemporâneo. 2. ed. São Paulo: Nova Fronteira, 1985.

COSTA, E. V. da. Da senzala a colônia.4. ed. São Paulo. Fundação Editora da UNESP, 1998.

Fernandes, W. O. Efeitos e Memória: A festa de narrativas vilabelenses. Dissertação (Mestrado em Linguística) Universidade do Estado de Mato Grosso, Cáceres, 2014.

GUIMARÃES, E. Análise de texto - Procedimentos, Análises, Ensino. Campinas: Editora RG, 2011.

. Os Limites do Sentido: um estudo histórico e enunciativo da linguagem. 2. ed. Campinas, SP: Pontes, 2002.

. Semântica do acontecimento: um estudo enunciativo da designação. Campinas, SP: Pontes, 2002.

ORLANDI, E. P. História das Idéias Linguísticas: construção do saber metalinguístico e constituição da língua nacional. Campinas, SP: Pontes; Cáceres, MT: Unemat Editora, 2001

Interpretação; autoria, leitura e efeitos do trabalho simbólico. 5. ed. Campinas, SP: Pontes Editores, 2007.

ZATTAR, N. B. da S. Os sentidos de liberdade dos escravos na constituição do sujeito de enunciação sustentada pelo instrumento da alforria. Dissertação (Mestrado em Linguística). Universidade Estadual de Campinas, Campinas, 2000.

Recebido em: agosto de 2017.

Aprovado em: outubro de 2017.

Como citar este trabalho:

FERNANDES, W. O.; SOUZA, F. G. DE; PRIA, A. D. Dança do chorado: reescriturações de sentidos para a dançarina. Traços de linguagem, v. 1, n. 2, p. 61-68, 2017. 


\begin{abstract}
ANEXO
Narrativa sobre o Chorado

A dança do Chorado foi uma estratégica usado pelas senhoras escravas no momento correto com a dancinha. Seus esposos e seus filhos presos, além de tudo isso e conhecimento da população, os sacrificios são dados até as solturas que eram feito diante da presença dessas senhoras. As senhoras tinham uma certa diferenciação: era bem melhor tratadas. Para inibir os sofrimentos dos seus esposos, elas tinham os seus patrões uma grande revolta dentro de si próprio. Então, através da inteligência da mulher, porque não dizer também de suas astúcias, elas conseguiram aproximarem dos senhores, no momento do qual eles se encontrava, festejando, e já um pouco tomado pelas bebidas forte da época. Elas acharam uma solução, reunindo-se, diversas mulheres, planejaram e compraram uma saída. Qual foi essa saída? Elas se engrenaram, vestiram muito bem das melhores maneiras possiveis do qual vocês já estão vendo as nossa representante da época. Então elas se aproximava dos seus patrões e do qual eles por serem solteirões, não deixaram de se aproximarem das senhoras e lançaram as suas conquistas. No momento certo, elas se dividiam. E pra não desfazerem diretamente dos seus patrões, elas aceitava alguma proposta, mas lançava as suas. Foi o que a liberdade dos prisioneiros e muitas vezes alguns já eram condenado a morte. E por aí ela conseguia algumas liberdades. Chegando-se capitãogenerais de nossa região, sofreu essa penetração, uma pequena mudança. Em vez delas sofrerem "ceias" dos patrões, elas foram convocadas por eles. E nessas convocações, eles que selecionavam e convocavam meninas mais jovens, mais bonitas e mais belas com o objetivo de satisfazerem seus desejos. E os tempos se passaram. Após a transferência da capital de Vila Bela pra Cuiabá, a festa do Chorado, a dança do Chorado, perderam seu sentido. Mas no entanto, as conselheiras da festança, assumiram essa responsabilidade, que ao final da festa, por elas não terem participado duma festança igual semelhante a essa, elas se reuniam em um determinado local, um pouco secreto, e "borrunfaram" os tambores. Elas convidavam alguns curiosos e que esses curioso entravam no recinto e lá eles eram amarrados por um lenço no pescoço considerado prisioneiro "a comprir-mir" com algumas bebida e alguns donativo para que elas também continuassem a participar da festança. Isso aí foi a longo prazo. A partir da década de 80, nós começamu organizar de uma forma bem melhor e cada dia que passa a festança tá criando mais "adeptos", tão criando mais aproximação com toda uma população do nosso país.
\end{abstract}

